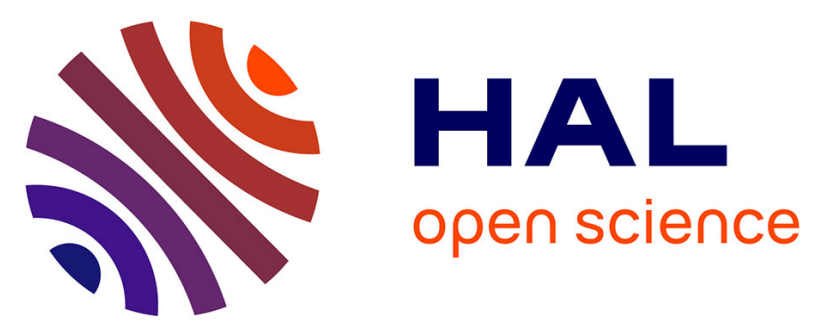

\title{
ANALYSIS OF THE CORRELATION BETWEEN KNEE EXTENSION TORQUE AND PATELLAR TENDON ELASTIC PROPERTY
}

P Mannarino, K M M Lima, C R C * Fontenelle, T T Matta, R Rouffaud, W C A Pereira, L F Oliveira

\section{To cite this version:}

P Mannarino, K M M Lima, C R C * Fontenelle, T T Matta, R Rouffaud, et al.. ANALYSIS OF THE CORRELATION BETWEEN KNEE EXTENSION TORQUE AND PATELLAR TENDON ELASTIC PROPERTY. Congresso Brasileiro de Engenharia Biomédica, Oct 2016, Foz de Iguaçu, Brazil. hal-01705133

\section{HAL Id: hal-01705133 \\ https://hal.science/hal-01705133}

Submitted on 22 Mar 2018

HAL is a multi-disciplinary open access archive for the deposit and dissemination of scientific research documents, whether they are published or not. The documents may come from teaching and research institutions in France or abroad, or from public or private research centers.
L'archive ouverte pluridisciplinaire HAL, est destinée au dépôt et à la diffusion de documents scientifiques de niveau recherche, publiés ou non, émanant des établissements d'enseignement et de recherche français ou étrangers, des laboratoires publics ou privés. 


\title{
ANALYSIS OF THE CORRELATION BETWEEN KNEE EXTENSION TORQUE AND PATELLAR TENDON ELASTIC PROPERTY
}

\author{
Mannarino, P. *, Lima, K. M. M. **, Fontenelle, C. R. C. *, Matta, T. T. **, \\ Rouffaud, R. **, Pereira, W.C.A.** and Oliveira, L. F.**. \\ * Clementino Fraga Filho University Hospital, UFRJ, Rio de Janeiro, Brazil \\ ** Biomedical Engineering Program, UFRJ, Rio de Janeiro, Brazil \\ e-mail: mannarino@ufrj.br
}

\begin{abstract}
Quadriceps strength and patellar tendon (PT) mechanical properties are directly linked and intimately related to daily activities and lower limb function. However, the correlation between knee extension torque (KT) and PT Young's modulus (E) directly measured is still unknown. We evaluated directly by means of supersonic shearwave imaging (SSI) the elastic properties of PT in healthy young men and analyzed its correlation with KT. Twenty-two healthy young males were included and both knees were examined. The EM of the PT in the dominant and non-dominant legs was assessed by SSI elastography. KT in maximal voluntary contraction was measured with an isokinetic dynamometer. No correlations between KT and PT EM were observed in dominant or non-dominant side $(\mathrm{p}=$ 0.458 and 0.126 , respectively). No significant differences in KT or PT E were observed between both legs $(p=0.096$ and 0.722 respectively). No significant correlations were found between KT and PT E, suggesting that quadriceps strength is not an accurate predictor for PT mechanical properties. PT habitual loading pattern can play a determinant role in determining its mechanical properties, regardless of quadriceps strength.
\end{abstract}

Keywords: Young's Modulus, patellar tendon, elastic properties, knee torque, supersonic shearwave imaging.

\section{Introduction}

Tendons are important connective tissue structures, responsible for transmitting muscle forces to produce normal joint motion and mechanical torque [1]. Its mechanical properties influence movement patterns and are fundamental to guarantee efficient force transmission but also reduced bone-tendon interface stress. The patellar tendon (PT) deserves particular interest for its function, being responsible for transmitting the quadriceps muscle strength, which is fundamental for lower limb movement, locomotion and normal daily activities [1]. Patellar tendon properties are directly related to the individuals loading environment [2-6], gender and age $[5,7,8]$ or previous existence of any tendon disorder $[9,10]$.

The PT is highly plastic, with changes in mechanical properties registered even in acute stretching or loading interventions [11, 12]. Furthermore, although resistance training (RT) focus is primarily on promoting muscle strength gains and increasing muscle mass and power [13], tendons also seem to benefit from chronic overloading [14-19]. It is worth noting that muscle adaptations happen faster than tendons' and therefore chronic studies trying to correlate increases in muscle strength and PT mechanical property changes after training can be limited by the nature of different structures remodeling rate [20]. In that context, habitual loading environments can be considered as valuable tools and were already performed [2-6].

The study of tendons viscoelastic properties has been of particular interest in the last decades. Initially, the assessment through calculation was made using Bmode ultrasonography (US) and magnetic resonance imaging (MRI) [5, 6, 8, 12, 19]. Although developed almost three decades ago [21], only recently ultrasound elastography was applied to directly determine PT elasticity in vivo [22]. In that context, supersonic shear imaging (SSI) rises as a valuable tool for PT evaluation $[2,7,10,11,22]$. SSI is able to determine directly the elasticity in a determined region of interest (ROI) without the need of further mathematics calculations [22], which is useful for different structures in large or small joints, in healthy or injury tendons $[9,10]$.

To the best of our knowledge, no previous studies investigated the association between PT function estimated by quadriceps contraction evaluation and its elastic properties measured by SSI in healthy young males. The main objective of our present study was to analyze the correlation between KT and the PT Young's modulus (E) measured with SSI in healthy young men with no previous history of knee injury. We hypothesized that quadriceps strength expressed as KT will not correlate with PT E in individuals that are not submitted to a specific training pattern or standard habitual loading environment.

\section{Materials and methods}

Ethics statement - The University Hospital Ethics Committee approved this study (registration numbers 570.945 and 519.230). The experimental procedures were conducted in accordance with the Declaration of Helsinki. All participants received instructions about the study procedures and provided informed written consent before testing.

Experimental procedure - The study was conducted at the Biomedical Engineering Department in 
our University. The body weight and height of all subjects were measured. Age and dominant leg was informed. All subjects were submitted to PT ultrasound evaluation and KT measure in two different days with a minimum one-week rest between them and both knees were examined in each session.

Subjects - In this cross-sectional study, 23 volunteer members of the University Hospital medical staff were selected and both knees were examined. Inclusion criteria were male sex and age between 25 and 35 years old to eliminate any variation of PT properties due to age or gender. Any clinical history or report of knee pain/injuries, systemic disease or previous knee surgery, was considered as exclusion criteria. One of the subjects with reported persistent knee pain during examination was excluded, remaining 22 participants. Their demographic characteristics are presented in Table 1. All subjects were right handed and right leg dominant.

Table 1: Characteristics of subjects in the study

\begin{tabular}{ll}
\hline Variables & $\mathrm{n}=22$ \\
\hline Age $($ years $)$ & $28.4 \pm 2.2$ \\
Height $(\mathrm{cm})$ & $179.0 \pm 7.4$ \\
Weight $(\mathrm{kg})$ & $87.9 \pm 11.4$ \\
BMI $\left(\mathrm{kg} / \mathrm{m}^{2}\right)$ & $27.2 \pm 2.6$ \\
\hline
\end{tabular}

Values shown as mean \pm standard deviation; $\mathrm{BMI}=$ body mass index.

Measurement of patellar tendon elastic modulus - An Aixplorer ultrasound (v.9, Supersonic Imaging, Aix-en-Provence, France) in conjunction with a $60-\mathrm{mm}$ linear-array transducer at $4-15 \mathrm{MHz}$ frequency was used in this study. The ultrasound transducer was positioned at the inferior pole of patella and aligned with the patellar tendon, with light pressure on top of a generous amount of coupling gel. B-mode was used to locate and align the patellar tendon longitudinally. When a clear image of the patellar tendon was captured, the shear wave elastography mode was then activated. The transducer was kept stationary for five seconds during the acquisition of the SSI map. A total of two images were captured for the tendon on each knee for off-line analysis.

Scanning of PT was performed with the subject in supine lying and the knee at $30^{\circ}$ of flexion [11]. The knee was supported on a custom-made knee and ankle stabilizer to keep the leg in neutral alignment on the coronal and transverse planes. Prior to testing, the subject was allowed to have a 10-min rest in both positions, to ensure the mechanical properties of patellar tendon were evaluated at resting status. The room temperature was controlled at $20^{\circ} \mathrm{C}$. The same experienced operator performed all exams. The ROI exhibited rectangular form to display more PT elasticity information (figure 1). An Aixplorer tool namely "Qbox tracing" obtained Young's modulus values and its limits were defined as the area between 5 and $20 \mathrm{~mm}$ from the inferior pole of the patella excluding the paratendon (Figure 1). Each tendon was measured twice.

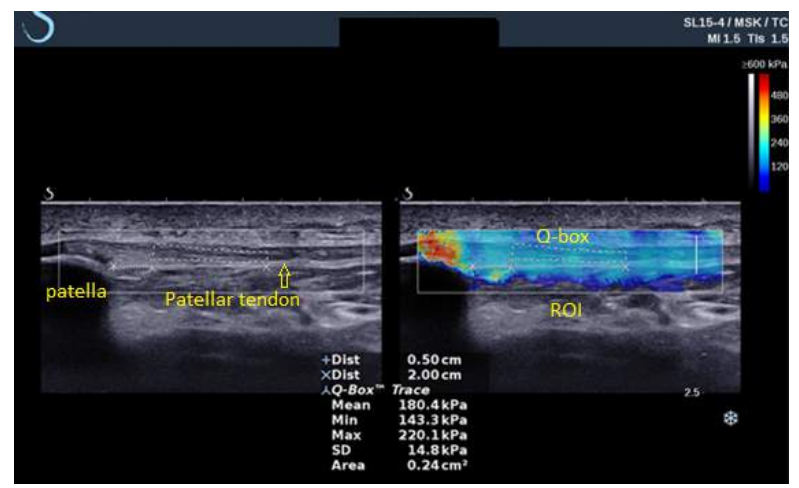

Figure 1: Rectangular ROI with Q-box tracing (dashed area) defined between 5 and $20 \mathrm{~mm}$ from the patella tip. The color scale (top right side) represents Young's modulus information and varied from 0 (blue) to 600 $\mathrm{kPa}$ (red).

Measurement of knee extension torque - The maximal isometric KT was measured with an isokinetic dynamometer (Biodex, Biodex Medical Systems, Shirley, NY, USA) at $70^{\circ}$ of knee flexion [23]. Subjects were positioned on the chair with inextensible straps fastened around the waist, trunk and distal part of the thigh. The backrest inclination and seat translation as well as the dynamometer height were adjusted for each subject, to ensure proper alignment of the rotation axis of the dynamometer with the lateral condyle of the femur. The right knee was fixed to the dynamometer lever arm $5 \mathrm{~cm}$ above the lateral malleolus. Settings were recorded for re-test reproducibility. After a specific warm-up consisting of two submaximal isometric knee extensions, the subjects performed two 5-s maximal voluntary isometric contractions (MVIC) with oneminute passive rest between trials. Subjects were verbally encouraged to reach maximal effort while a visual feedback of the torque level was provided. The highest peak torque among trials (corrected for gravity) was recorded for analysis.

Statistical Analysis - Descriptive data such as mean \pm SD were calculated. After the normality distributions were assumed using the Shapiro-Wilk tests, paired ttests were used to compare the KT and E of the PT between the dominant and non-dominant sides. Pearson correlation coefficient was used to investigate the association between the PT E and KT. The dependent measure for analysis was the averaged mean tendon $\mathrm{E}$ from two images of the PT taken. A p value of 0.05 was considered as significant.

\section{Results}

Side-to-side differences - No side-to-side differences on the outcome measures were observed in the subjects (Table 2). There were no significant differences on the PT E or KT between the dominant and non-dominant sides $(\mathrm{p}>0.05)$. 
Table 2. Side-to-side differences in patellar tendon Young's modulus and knee extensor torque

\begin{tabular}{llll}
\hline Variables & $\begin{array}{l}\text { Dominant } \\
\text { side } \\
\mathrm{n}=22\end{array}$ & $\begin{array}{l}\text { Non- } \\
\text { dominant } \\
\text { side } \\
\mathrm{n}=22\end{array}$ & $\begin{array}{l}\mathrm{p} \\
\text { Value }\end{array}$ \\
\hline $\begin{array}{l}\text { Young's } \\
\text { modulus }(\mathrm{kPa})\end{array}$ & $118.8 \pm 52.4$ & $137.8 \pm 64.9$ & 0.722 \\
$\begin{array}{l}\text { Extensor } \\
\text { torque }(\mathrm{Nm})\end{array}$ & $305.3 \pm 50.3$ & $307.9 \pm 54.1$ & 0.096 \\
\hline
\end{tabular}

Values shown as mean \pm standard deviation.

Correlations - No significant correlations were observed between knee extension torque and Young's modulus in both dominant and non-dominant sides (figures 2 and 3).

\section{Dominant side}

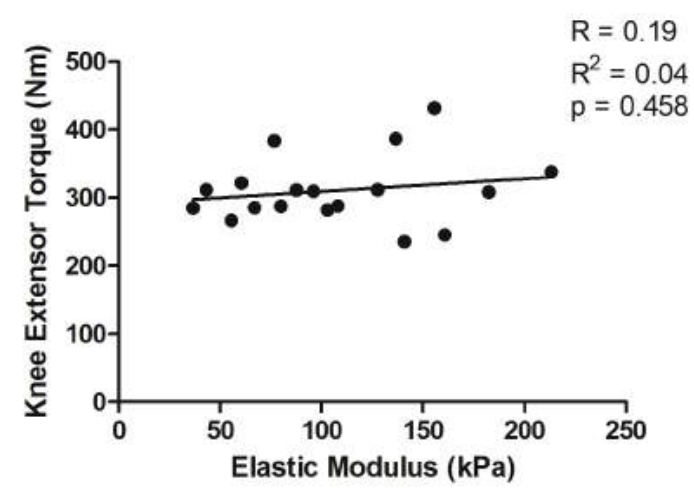

Figure 2. Correlation between knee extension torque and patellar tendon Young's modulus, dominant side.

Non-dominant side

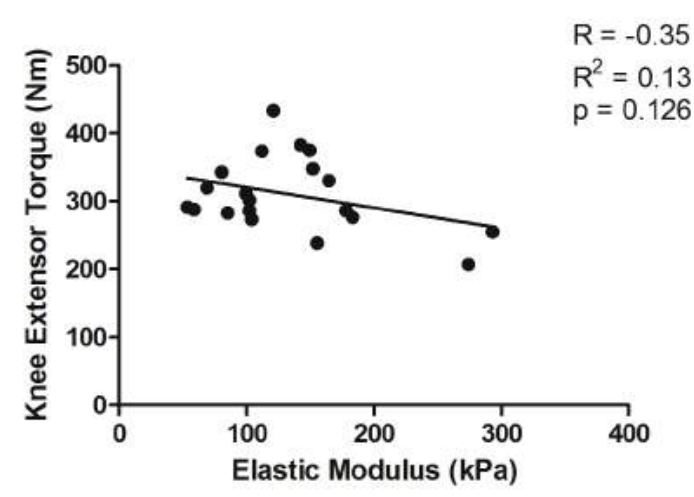

Figure 3. Correlation between knee extension torque and patellar tendon Young's modulus, non-dominant side.

\section{Discussion}

This study aimed to assess the effect of habitual loading on tendon mechanical property and to verify the correlation between KT and PT thickness and E measured by means of SSI. Findings indicate that PT E is not correlated to KT in healthy young males with random levels of physical activity.
It is well documented that PT mechanical properties are changed after RT protocols or other sports engagement [14-19], however the effects of long-term (years) training on tendon adaptations were less studied [20]. It is practically unanimous that RT strategies improve muscle strength and promote significant increases in PT stiffness and E. RT demands the tendon unit as a rigid force transmitter, therefore the higher the Young's modulus, better for tendon function [20]. On the other hand, activities that include high impact and repetitive stretch shortening cycle (i.e. volleyball, basketball) seem to decrease the PT E [2] even though promoting strength gains. Therefore, relation between quadriceps strength and PT properties should not be analyzed from the RT perspective alone since changes in elastic properties seen inherent to sports or training characteristics.

Based on this previous evidence, our initial hypothesis was that quadriceps strength, expressed as KT, would not correlate with PT elastic property (E). Our results showed no correlation between PT E and KT what was coherent with the null hypothesis.

We recognize some study limitations that should be considered and can be divided in sample composition and study design. First, we used a convenience sample composed of healthy young male volunteers from the medical staff of our university hospital. No differentiation was made between the previous activity levels with some of them declaring to be regularly engaged on RT, others recreationally actively practicing soccer or running and a few were sedentary. These random levels of activity and previous sports practice may mask results that would be seen in a more homogeneous sample, since tendon properties are related to function. Also, these findings cannot be generalized to females, other age range or a specific athletic population. At last, the leg preference in the present study was self-reported and no experimental assessment of hand or leg preference was done.

Moreover, this was a cross-sectional observational study; no causal effects could be analyzed. Potential confounding factors such as physical activity levels and nutrition were not accounted for, although all the participants were free of systemic disease. Additional longitudinal trials are warranted for further clarification of the effect of quadriceps on PT properties. Furthermore, interventions protocols should provide an insight of how tendon adapts when examined in the light of SSI.

\section{Conclusion}

The present study revealed no significant differences in PT Young's modulus and KT between right and left legs in healthy young men, suggesting that in similar loading environments side dominance does not affect these parameters. No significant correlations where established between KT and PT E in both sides, suggesting that quadriceps strength alone is not an accurate predictor for PT mechanical property. More studies analyzing changes in E after training should 
provide further understanding on tendon mechanical adaptations to loading and different loading patterns.

\section{Acknowledgements}

The authors are thankful for the financial support of CAPES, CNPq, FINEP and FAPERJ. The authors have no conflicts of interest.

\section{References}

[1] Józsa, L.G. and P. Kannus, Human tendons: anatomy, physiology, and pathology. 1997: Human Kinetics Publishers.

[2] Zhang, Z.J., G.Y. Ng, and S.N. Fu, Effects of habitual loading on patellar tendon mechanical and morphological properties in basketball and volleyball players. Eur J Appl Physiol, 2015. 115(11): p. 2263-9.

[3] Couppe, C., et al., Habitual loading results in tendon hypertrophy and increased stiffness of the human patellar tendon. J Appl Physiol (1985), 2008. 105(3): p. 805-10.

[4] Kubo, K., et al., Effects of mechanical properties of muscle and tendon on performance in long distance runners. Eur J Appl Physiol, 2010. 110(3): p. $507-14$.

[5] Westh, E., et al., Effect of habitual exercise on the structural and mechanical properties of human tendon, in vivo, in men and women. Scand J Med Sci Sports, 2008. 18(1): p. 23-30.

[6] Seynnes, O.R., et al., Effect of androgenicanabolic steroids and heavy strength training on patellar tendon morphological and mechanical properties. J Appl Physiol (1985), 2013. 115(1): p. 84-9.

[7] Hsiao, M.Y., et al., Reduced Patellar Tendon Elasticity with Aging: In Vivo Assessment by Shear Wave Elastography. Ultrasound Med Biol, 2015. 41(11): p. 2899-905.

[8] Onambele, G.N., K. Burgess, and S.J. Pearson, Gender-specific in vivo measurement of the structural and mechanical properties of the human patellar tendon. J Orthop Res, 2007. 25(12): p. $1635-42$

[9] Ooi, C.C., et al., A soft patellar tendon on ultrasound elastography is associated with pain and functional deficit in volleyball players. J Sci Med Sport, 2015.

[10] Zhang, Z.J., et al., Changes in morphological and elastic properties of patellar tendon in athletes with unilateral patellar tendinopathy and their relationships with pain and functional disability. PLoS One, 2014. 9(10): p. e108337.

[11] Zhang, Z.J. and S.N. Fu, Shear Elastic Modulus on Patellar Tendon Captured from Supersonic Shear Imaging: Correlation with Tangent Traction Modulus Computed from Material Testing System and Test-Retest Reliability. PLoS One, 2013. 8(6): p. e68216.

[12] Svensson, R.B., et al., Mechanical properties of human patellar tendon at the hierarchical levels of tendon and fibril. J Appl Physiol (1985), 2012. 112(3): p. 419-26.

[13] American College of Sports Medicine, M., American College of Sports Medicine position stand. Progression models in resistance training for healthy adults. Med Sci Sports Exerc, 2009. 41(3): p. 687-708.

[14] Malliaras, P., et al., Patellar tendon adaptation in relation to load-intensity and contraction type. J Biomech, 2013. 46(11): p. 1893-9.

[15] Kongsgaard, M., et al., Region specific patellar tendon hypertrophy in humans following resistance training. Acta Physiol (Oxf), 2007. 191(2): p. 111-21.

[16] Grosset, J.F., et al., Influence of exercise intensity on training-induced tendon mechanical properties changes in older individuals. Age (Dordr), 2014. 36(3): p. 9657.

[17] Kubo, K., et al., Effects of isometric training on the elasticity of human tendon structures in vivo. Journal of Applied Physiology, 2001. 91(1): p. 2632.

[18] Reeves, N.D., C.N. Maganaris, and M.V. Narici, Effect of strength training on human patella tendon mechanical properties of older individuals. J Physiol, 2003. 548(Pt 3): p. 971-81.

[19] Seynnes, O.R., et al., Training-induced changes in structural and mechanical properties of the patellar tendon are related to muscle hypertrophy but not to strength gains. J Appl Physiol (1985), 2009. 107(2): p. 523-30.

[20] Wiesinger, H.P., et al., Effects of Increased Loading on In Vivo Tendon Properties: A Systematic Review. Med Sci Sports Exerc, 2015. 47(9): p. 1885-95.

[21] Ophir, J., et al., Elastography: A Quantitative Method for Imaging the Elasticity of Biological Tissues. Ultrasonic Imaging, 1991. 13(2): p. 111134

[22] Kot, B.C., et al., Elastic modulus of muscle and tendon with shear wave ultrasound elastography: variations with different technical settings. PLoS One, 2012. 7(8): p. e44348.

[23] Blazevich, A.J., et al., Anatomical predictors of maximum isometric and concentric knee extensor moment. European journal of applied physiology, 2009. 105(6): p. 869-878 